\title{
AC 2008-58: THE EVOLUTION OF PROFESSIONAL ASSOCIATIONS, ENGINEERING EDUCATION AND INFORMATION LITERACY
}

\section{Carol Johnson, New Jersey Institute of Technology}

Carol Siri Johnson is an Assistant Professor of Humanities at New Jersey Institute of Technology. Her undergraduate degree is from Mount Holyoke College and her Ph.D. is from the Graduate Center of the City University of New York. Her research areas include technical communication in the American iron and steel industry and educational assessment. 


\title{
The Evolution of the Professional Associations, Engineering Education and Information Literacy
}

\begin{abstract}
Change has become a constant in our society, especially in methods of creating and transferring knowledge. In the $19^{\text {th }}$ century, the professional associations pioneered rapid knowledge acquisition and transfer as groups formed, met, and shared ideas that led to more ideas. Associations such as the ASCE, AIME and ASME were the original knowledge owners and brokers, building libraries, publishing transactions and instituting professional requirements that entitled the bearer to such designations as M. E. and C. E. College education began in America in the $19^{\text {th }}$ century as well, but it was not until after the Morrill Land Act and the colleges' gradual growth that they had to power to become the primary disseminators of knowledge. After the colleges were firmly established, they took over the credentialing of engineers including the granting of degree titles. At this point, the associations began to withdraw from the business of education and knowledge management. They combined their libraries and offices in single location: the Engineering Societies Library in New York City. As technology became more complex, the associations splintered into smaller groups, weakening the original structures. By the late $20^{\text {th }}$ century, the Engineering Societies Library was disbanded as well. In the $21^{\text {st }}$ century, the transmission of knowledge has moved beyond both the associations and the universities to a wide array of resources that require information literacy to penetrate.
\end{abstract}

\section{The Evolution of the Professional Associations in the $19^{\text {th }}$ Century}

The American Society of Civil Engineers and Architects was established in 1853 but was not active until 1868, when they changed their name to The American Society of Civil Engineers (ASCE). ${ }^{1}$ They began to publish their Transactions in 1868 and their Proceedings in 1873. The American Institute of Mining Engineers (AIME) was founded in 1871 and grew rapidly. It regularly published the Transactions of the American Institute of Mining Engineers as well as using a weekly, the Engineering and Mining Journal as its official "organ". The American Society of Mechanical Engineers (ASME) was founded in 1880, grew rapidly and also immediately began publishing Transactions. The American Institute of Electrical Engineers (later the IEEE) was founded in 1884. The purpose of these associations, based on the scientific societies in Europe, were "to promote the Arts and Sciences connected with the [industry] . . by means of meetings for social intercourse, and the reading and discussion of professional papers, and to circulate, by means of publications among its members and associates, the information thus obtained." 3 These societies were able to emerge at this time because railroads connected distant cities and allowed relatively rapid travel to meeting locations. Both regional and national meetings were held in a variety of locations throughout each year. The center of industry, however, was the northeast United States. Later, these founder organizations consolidated their libraries and offices in a single building in New York City.

All of these organizations were structured like the scientific and technological associations in Europe. They were "complex systems of knowledge and the associated means of diffusing and advancing those systems ... that closely paralleled the knowledge systems and professional institutions of the sciences" in Europe. ${ }^{5}$ They traded knowledge via personal 
interaction, organized visits to industrial sites, paper presentations and discussions and the publication of the papers and transcribed discussions. They allowed people to meet who had different areas of expertise to share their knowledge and thus they were a strong impetus for intellectual and technological growth in the $19^{\text {th }}$ century. The publications were also able to reach those who did not attend the meetings and formed a repository of current knowledge that could aid in the advancement of the industry.

The requirements for admission into to professional associations varied, but overall they included being an active participant within the profession for a certain number of years, most often at a supervisory level. Members were invited to join and then formally accepted by vote. Thus, in the $19^{\text {th }}$ century it was difficult for a young engineer with no experience to join. The ASCE required "active employment in the profession for five years in the capacity or rank of Superintending Engineer" and in 1873 the ASCE President confirmed in his address that the Society "was not a school for training young engineers." The members of the associations were professionals who were proud of their achievements and distinguished themselves from others by initials after their name: M. E. for mechanical engineer, C. E. for civil engineer, E. M. for engineer of mining, etc. Engineers with college degrees sometimes used their degree initials and sometimes did not. Some professional engineers "resented college-trained engineers of both mediocre social and intellectual background" and felt that colleges did not prepare engineers adequately for practice. ${ }^{6}$ During the end of the $19^{\text {th }}$ century, a dispute arose as to who should have the right to display the initials after their name. Much of the dispute took place in essays and letters to professional journals and weeklies, but some of it took place on the college campuses themselves as they tried to define the future. As Monte Calvert wrote in The Mechanical Engineer in America, 1830-1910:

The conflict between shop and school began in the late 1860's when the first engineering schools for mechanical engineers were set up, intensified from 1880 to 1890 - the formative period of the ASME - was followed by a period of self-examination and compromise from 1890 to 1905 , and ended with the ascendancy of the school forces after 1905. By this last date the engineering schools were in more or less full control of the training process of mechanical engineers. ${ }^{6}$

The dispute over the use of titles was more than just an indicator of status: mid-century engineers achieved great accomplishments without holding college degrees. At that point, engineering knowledge existed mainly within working engineers and professional associations. Later, the base of knowledge shifted to colleges and universities (and the degree titles moved with it).

\section{The Evolution of Engineering Education in the $19^{\text {th }}$ Century}

In the $19^{\text {th }}$ century, just as engineering advances were radically transforming society, our educational system was changing as well. Some American colleges had imported the educational systems of Europe, just as the professional associations had imported their models. In many colleges, the study of Latin and Greek was just being broadened to include English when two new subjects, engineering and science, made their appearance on the educational stage. Like the tug-of-war over titles between the professional societies and the colleges, the early evolution of engineering education was fraught with contention: some universities felt that engineering was not a fit subject to teach, faculty were hard to find, faculty did not always have degrees, curricula were as yet unformed, and there were no names for engineering degrees. In 
1870, college graduates comprised less than one-ninth of the engineering workforce. ${ }^{7}$ A solid educational structure had to be built in order to train larger numbers of engineers.

Change was a part of engineering education from the beginning. In Democracy's College: The Land-grant Movement in the Formative State, Earle Ross wrote that United States colleges evolved with "a free and regionally varied experimentation." " Throughout this process of growth and experimentation, the addition of science to the curriculum was the paradigm that shattered the classical curricula. Ross wrote "The innovation that was ultimately to work the greatest revolution in modern education was the movement to develop the natural and physical sciences as regular and coordinate subjects.". When the Lawrence Scientific School at Harvard began, it was "in the face of an unconcealed disdain on the part of the regular faculty. ${ }^{7}$ Some universities felt that science and engineering were not subjects fit to be taught in a university setting. "There could be no large development until the monopoly of classical learning was broken ...." Nearly 700 colleges failed in the United States before 1860: "Often when a college had a building, it had no students. If it had students, frequently it had no building. If it had either, then perhaps it had no money, perhaps no professors; if professors, then no president, if a president, then no professors."10 The addition of science and engineering to the curriculum was fundamental to the growth of American education but it took a federal act to guarantee its growth.

The Morrill Federal Land Grant Act in 1862 provided a foundation for a new educational system. It granted each state public lands that could be sold and the proceeds used to build and endow colleges. Its goal was to teach agriculture and the mechanic arts (without excluding scientific and classical studies). ${ }^{10}$ In the east they were able to use the money to fund existing colleges, as well as build new ones. In the Midwest and west, however, many colleges had to be created from the ground up and thus they were even less tied to tradition than the eastern schools. The creation of new colleges was difficult: "There was an absence, for instance, of secondary schools available to farm children; a shortage of trained natural science teachers; no trained teachers of agriculture; not even, really, a science of agriculture." ${ }^{4}$ The same could be said of the mechanic arts. In 1860 there were only four engineering schools in America, but by 1870 that number had risen to seventeen. By 1871 there were forty-one, by 1872 seventy, and by 1880 eighty-five. By 1918, there were 126 engineering schools, forty-six of which were land grant colleges. ${ }^{7}$ Thus, the Land Grant Act "became one of the great forces of economic and social mobility in American society; it brought the government, both federal and state, firmly into the support of higher education. In the land-grant institutions the American people achieved popular higher education for the first time." ${ }^{\text {"10 }}$ Knowledge had begun to be available on a wider scale.

Public colleges became established by the end of the $19^{\text {th }}$ century. The ongoing debate about who should have the right to award degrees - the professional associations or the college continued until 1905 when educators acquired a voice in the councils of the ASME, compromises were made and the market for engineering, in general, was expanding. ${ }^{6}$ An educational system had been built that was strong enough to give graduates a basic education from which they could further their careers; the acquisition of knowledge had been systematized so that it could reach a larger number of people. The number of professional engineers continued to grow: 
There were only around 40,000 engineers in America in 1900, but by 1950 there were well over 500,000 and by 1990 around 2 million. Simultaneously the proportion of the work force made up of engineers increased, from 13 per 10,000 workers in 1900 to 128 per 10,000 workers by 1960 . By mid-century engineering had become the largest single occupation pursued by American males and the second largest of the occupations claiming professional status [outnumbered only by public school teachers]. ${ }^{4}$

Engineering knowledge had moved from the purview of the members of the professional associations to the colleges and universities.

\section{Changing Patterns of Knowledge Acquisition and Transfer in the $20^{\text {th }}$ Century}

After the Morrill Land Act and the formation of engineering programs, the professional societies remained strong conduits for advancing knowledge. They continued their publications of proceedings and transactions. Periodicals remain the most important source of new information for scientists and engineers. ${ }^{1}$ However, overall, the associations were getting out of the education business. In 1910 a new group formed, the Society for the Promotion of Engineering Education (SPEE), which eventually became the ASEE, which took up this charge. In 1904 the founding associations, ASCE, ASME, AIME, IEEE, joined in a project to house their offices at a single location and combine their libraries in a single collection open to the public. Andrew Carnegie provided \$1,050,000.00 for a library and office building in New York City. ${ }^{1}$ Later the American Institute of Chemical Engineers (AIChE) joined this group, forming the United Engineering Society. At first, each society maintained its own section of the library. The early library was a simple affair: if there were librarians, they had no offices in which to work so they worked in the main reading room (Fig. 1). ${ }^{1}$

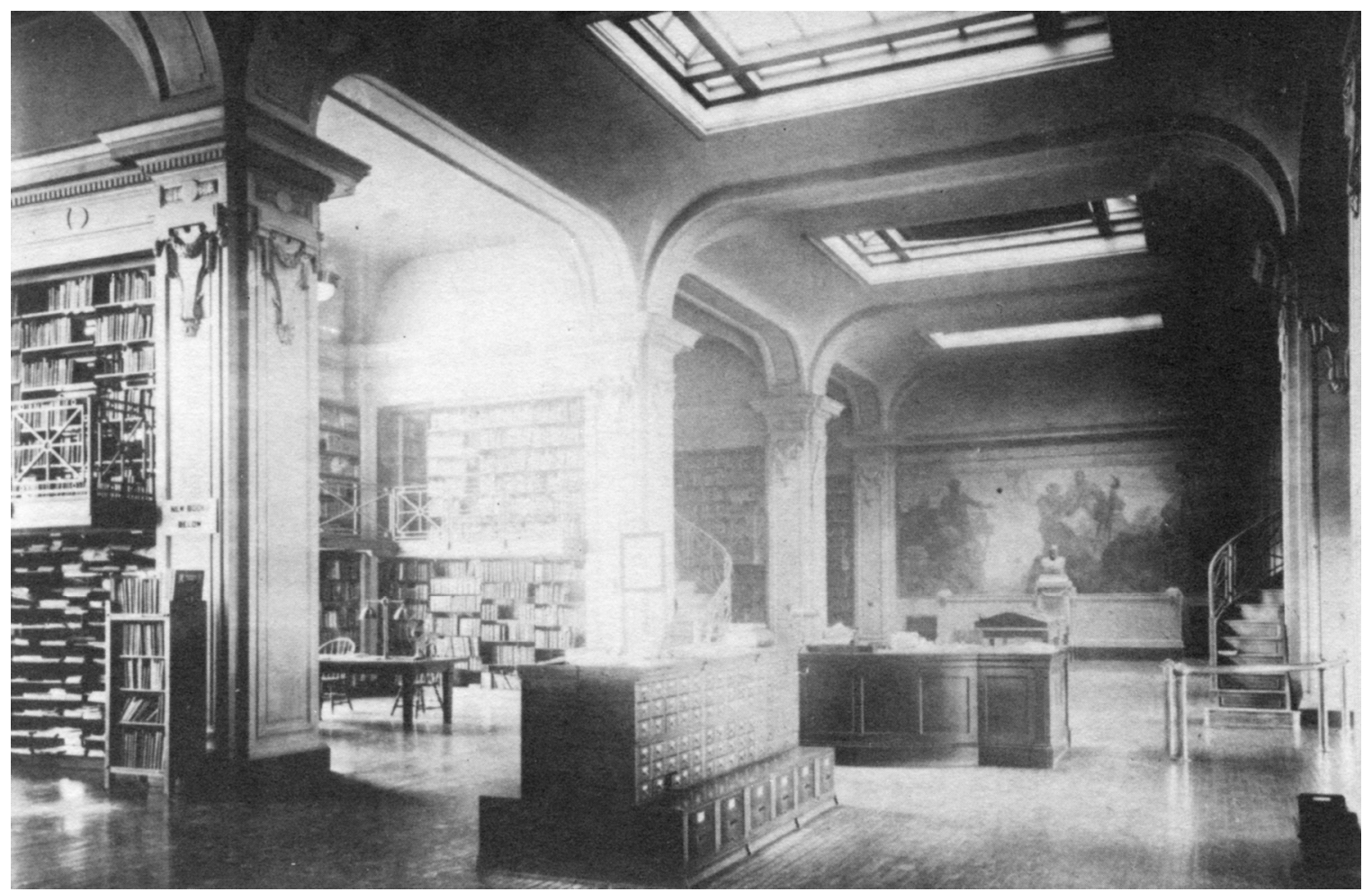

Figure 1 - Main Reading Room of the Engineering Societies Library, built in 1906. 
The library quickly outgrew its original space and a new building, near the United Nations, was dedicated by the former President Herbert Hoover in $1959 .{ }^{11}$ This was called the United Engineering Center and it housed one of the best engineering libraries in the world (Figs. 2 and 3). The library was especially useful during World War I and World War II when many branches of the government came looking for information. ${ }^{12}$ The library kept old standards, unlike many corporations and institutions that discard them when they have been superseded. Thus, they were contacted frequently by engineers from distant locations who needed the specifications for older structures and parts. ${ }^{13}$ The library continued to receive and catalogue periodicals and new publications and continued to grow.

The Engineering Index, now available as Compendex, began as an annual in 1884 but became a monthly in 1906, when the library opened. ${ }^{14}$ It was closely associated with the library and, like the library, frequently suffered financial problems. The growing body of knowledge in engineering literature was vast: the sheer number of monographs, journal publications from around the world, technical reports and conference proceedings was difficult to keep up with. Since engineers are problem solvers, they use all forms of published material, including older data and data from the sciences; "the scope of engineering had become enormous." 14 It was beyond the scope of the ever-splintering professional associations and even the universities to be able to contain and maintain all of this information. 


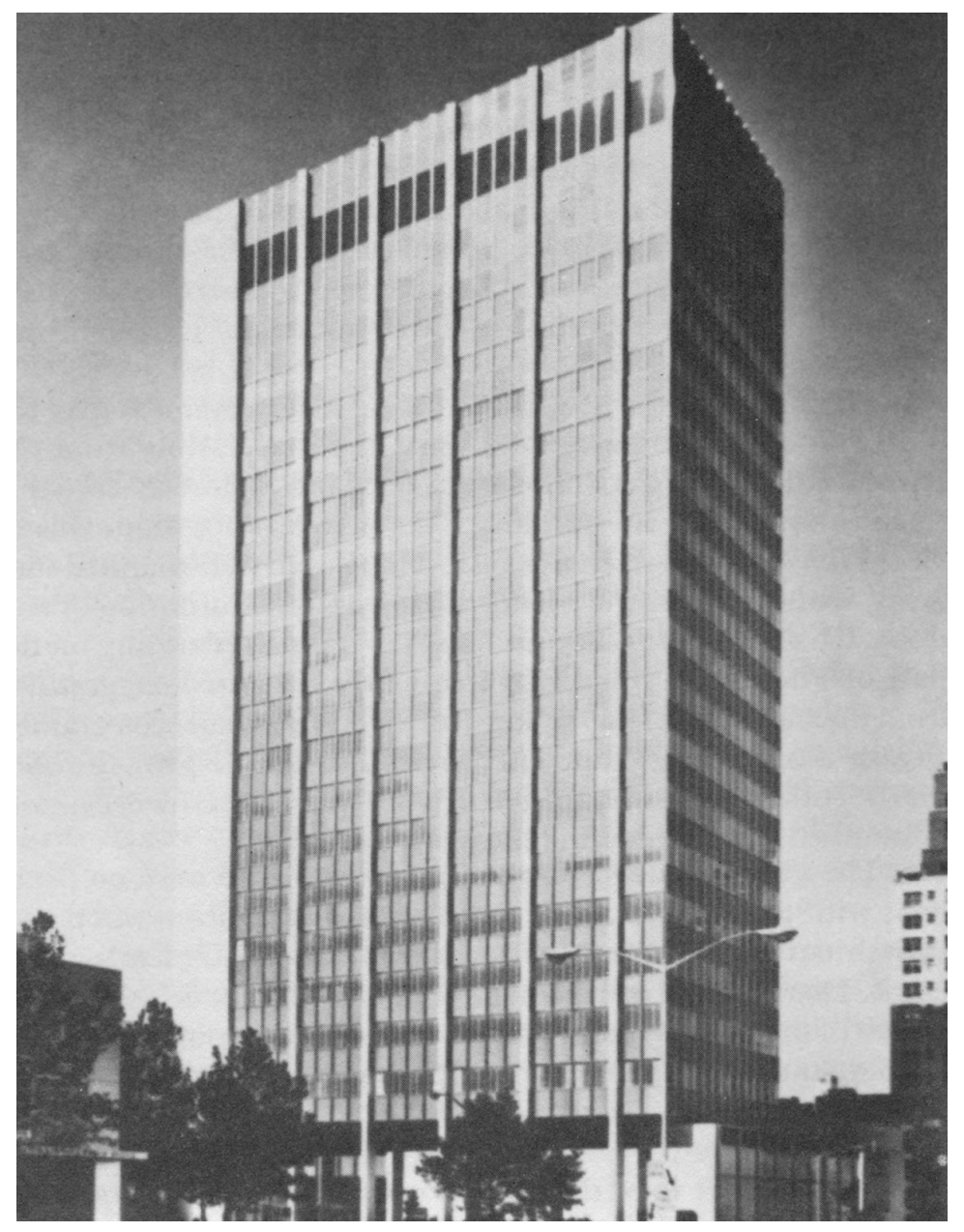

Figure 2 - United Engineering Center, completed in 1961.

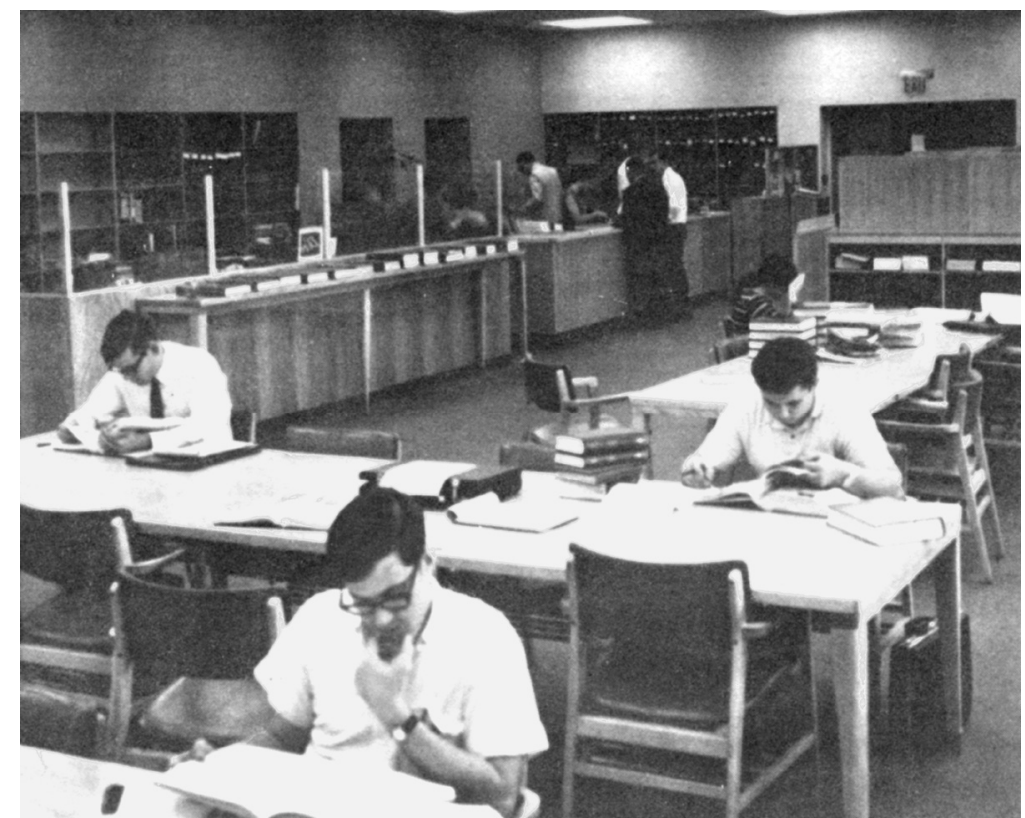

Figure 3 - New Engineering Societies Library Reading Room.

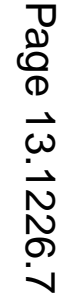


Even as this growth was happening, demographic and economic changes were occurring that would change the knowledge-base housed in the library. First, in modern corporate business structures professional associations are not as important to knowledge generation and transfer as they once were. As Terry Reynolds wrote, "they lost some of their cohesiveness and increasingly restricted their activities only to areas where consensus could be achieved, usually organizing meetings and publishing journals." ${ }^{, 4}$ Bruce Sinclair points out that, even though the majority of American male professionals are engineers, 75 to 80 percent "do not belong to their national societies and do not participate in the activities of those organizations. ${ }^{15}$ The professional associations begun to splinter as work became more complex and knowledge more specific: at the turn of the century there were nine major technical societies but by 1950 there were twenty-seven. ${ }^{4}$ The tendency towards fragmentation continued. ${ }^{16}$ Knowledge was becoming more disperse as networks with nodes replaced organized structures and fixed repositories. Engineering Societies Library, as useful as it was, cost money to operate and, increasingly, the societies did not want to fund the growing database.

Carnegie's initial gift to the United Engineering Societies carried it for a long time. However, since it was no longer in the interest of the professional societies to serve as a clearing house and distributor of knowledge, much of which was historical, the library was perpetually under funded. Document delivery services took advantage of this situation. These companies were hired by engineering firms to look up specific information. They, in turn, hired knowledge brokers called "runners" who would find the information. Since the library was continually understaffed, the runners had full access to the stacks. Since the runners were in competition with other runners, they sometimes hid documents so that only they would have access to them. ${ }^{13}$ What once was a monument to American engineering was disintegrating.

The library closed in 1998. The majority of it moved to Linda Hall Library in Kansas City, Missouri. The Engineering Societies' building near the United Nations was sold to Donald Trump. ${ }^{11}$ Although it is a change that the library is no longer in New York, it is also evidence that our methods of knowledge retrieval and transfer have broadened their scope: users of the library can still access the information they need via the internet, email, fax and phone. The United Engineering Foundation now grants money ( $\$ 700,000$ to $\$ 800,000$ projected for 2009) to professional associations such as the ASCE, IEEE, ASME, and new groups such as the National Action Council for Minorities in Engineering (NACME) for advancing engineering education. ${ }^{17}$ Now, colleges, universities, associations, industry, database providers such as the engineering index, libraries and the publishing industry all provide parts of the network of engineering knowledge that is always growing and changing. Methods of searching the databases have become so complex that most prefer to have searches performed by intermediaries. ${ }^{14}$ The information age, so some extent, has led to information confusion.

\section{Conclusion}

Change is a constant. This constant is new: prior to the $19^{\text {th }}$ century hundreds of years passed with minimal technological, professional and educational change. "For the oral traditions passed from master to apprentice, the new technologist substituted a college education, a professional organization, and a technical literature patterned on those of science." ${ }^{.18}$ In 1973, 
George Emmerson stressed, in his history of engineering education, is that American colleges continually experimented with their curricula and still do so today. ${ }^{16}$ In 1999, Bruce Seely wrote "Perhaps the most constant feature of American engineering education has been the demand for change." 19 Several authors have noted that frequent and comprehensive reports have been prepared on the history of engineering education: the Mann Report in 1918, the Wickenden Report in 1929, the Hammond Reports of 1940 and 1945, the Grinter Report of 1956 and the Walker, Hawking and Pettit Report of $1968 .{ }^{16}$ Change in engineering education is a constant in other countries as well: "Over the past two decades, virtually every country in the world that produces engineering graduates has been rethinking and restructuring the contents of engineering education." 20

Knowledge was first embodied in the craftsperson or worker; then it was a product of the professional associations that met and brainstormed in order to create and improve technologies; gradually knowledge was institutionalized in our universities; today it is in so many places that a high level of information literacy is required to retrieve it. Engineering knowledge can be in corporate reports, databases, indexes, proceedings, publications, raw data from experiments, standards, CD-ROMs, books, websites, patents, white papers and more. The relative simplicity of the past has been replaced with a complexity that we cannot yet fully understand.

\section{End Notes}

1. E. Mount, Ahead of It's Time: The Engineering Societies Library, 1913-1980, Hamden, CT: Linden Books, 1982.

2. "Publisher's Announcement," The Engineering and Mining Journal, 1872.

3. Transactions of the American Institute of Mining Engineers, Philadelphia, PA: The Institute, 1873.

4. T. S. Reynolds, The Engineer in America: A Historical Anthology from Technology and Culture, Chicago: University of Chicago Press, 1991.

5. R. H. Merritt, Engineering in American Society 1850-1875, Lexington, KY: University Press of Kentucky, 1969.

6. M. Calvert, The Mechanical Engineer in America 1830-1910, Baltimore, MD: Johns Hopkins University Press, 1967.

7. C. R. Mann, A Study of Engineering Education Prepared for the Joint Committee on Engineering Education of the National Engineering Societies, New York City: The Carnegie Foundation for the Advancement of Teaching, 1918.

8. Ross, E.D., Democracy's College: The Land-Grant Movement in the Formative Stage, Ames: Iowa State College Press, 1942.

9. W. E. Wickenden, "A Comparative Study of the Engineering Education in the U.S. And Europe. Report of the Investigation of Engineering Education," Pittsburgh, PA: Lancaster Press, the Society for the Promotion of Engineering Education. 1929.

10. F. Rudolph, The American College and University: A History. 1990 ed., Athens, GA: University of Georgia Press, 1962.

11. Cohen, A., "ESL: Engineering Sciences Library: End of a Special Library," Science \& Technology Libraries, 19(1): 2000, pp. 3-20. 
12. E. Mount, History of the Engineering Societies Library, 1913-1973, New York: Columbia University Dissertation, 1979.

13. Scharf, D., Personal Interview, 2007.

14. C. G. Gould and K. Pearce, Information Needs in the Sciences: an Assessment, Mountain View, CA: The Research Libraries Group, 1991.

15. B. Sinclair, "Local History and National Culture: Notions on Engineering Professionalism in America," in in The Engineer in America: A Historical Anthology from Technology and Culture, T. S. Reynolds, ed., Chicago, IN: University of Chicago Press, 1971.

16. Emmerson, G.S., Engineering Education: A Social History, New York: Crane, Russak, 1973.

17. United Engineering Foundation, <http://www.uefoundation.org/>, accessed Feb. 21, 2008

18. E. T. J., Layton, "Mirror-Image Twins: The Communities of Science and Technology in 19th-Century America," in The Engineer in America: A Historical Anthology from Technology and Culture, T. S. Reynolds, ed., Chicago, IN: University of Chicago Press, 1971.

19. B. E. Seely, "The Other Re-Engineering of Engineering Education, 1900-1965," Journal of Engineering Education, July, pp. 285-294,1999.

20. G. L. Downey and J.C. Lucena, "Knowledge and Professional Identity in Engineering: Code-Switching and the Metrics of Progress," History and Technology, 20(4): p. 393420, 2004. 